\title{
Direct Oral Anticoagulants for Paediatrics and Inherited Thrombophilia: Why Not?
}

\author{
Leonardo Di Gennaro ${ }^{1 *}$ and Claudia Riccio ${ }^{2}$ \\ ${ }^{1}$ Unità Operativa Malattie Emorragiche e Trombotiche, Fondazione Policlinico Universitario, Italy \\ ${ }^{2}$ Dipartimento di Scienze di Laboratorio e Infettivologiche, Fondazione Policlinico Universitario, Italy
}

*Corresponding author: Leonardo Di Gennaro, Unità Operativa Malattie Emorragiche e Trombotiche, Area di Ematologia, Fondazione Policlinico Universitario “Agostino Gemelli”, IRCCS, Italy.

To Cite This Article: Leonardo Di Gennaro. Direct Oral Anticoagulants for Paediatrics and Inherited Thrombophilia: Why Not?. Am J Biomed Sci \& Res. 2019 - 5(1). AJBSR.MS.ID.000866. DOI: 10.34297/AJBSR.2019.05.000866

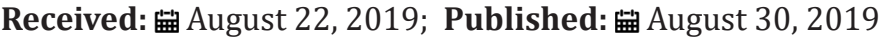

\begin{abstract}
Direct oral anticoagulants (DOAC) are indicated in the treatment and prevention of venous thromboembolism (VTE). However, the use of DOAC in paediatrics VTE, and in patients with inherited thrombophilia remains controversial due to the paucity of available data. However, the efficacy of DOAC may be suitable in children and in patients with thrombophilia. Randomized clinical trials, which are currently underway, should offer definitive insight into the efficacy and safety profiles of DOAC in these patient populations.
\end{abstract}

Keywords: Direct oral anticoagulant; Inherited thrombophilia; Venous thromboembolism; Paediatrics; Personalized therapy

Abbreviations: DOAC: Direct Oral Anticoagulant Drugs; VTE: Venous Thromboembolism.

\section{Introduction}

Direct oral anticoagulants (DOAC) are largely indicated in the acute treatment and secondary prevention of venous thromboembolism (VTE), which includes deep venous thrombosis and pulmonary embolism [1,2]. All the recent guidelines confirm efficacy and safety of DOAC for both acute and long-term treatment of VTE $[3,4]$. Furthermore, the guidelines on Antithrombotic Therapy for VTE disease from the American College of Chest Physicians recommend choosing anticoagulant therapy based on patient specific factors such as age, weight, renal or liver disease, but also adherence and patient preference, instead of more traditional treatment such as vitamin $\mathrm{K}$ antagonist therapy [2]. However, guidelines do not provide specific guidance for the treatment of VTE in paediatrics or in patients with inherited thrombophilia, only mentioning inherited thrombophilia disorders as a risk factor for recurrent VTE. Moreover, although DOAC seem to bring significant improvements in terms of quality of life and therapeutic adherence in children or in the chronic treatment of inherited thrombophilia, many paediatric patients with VTE and hereditary thrombophilia continue treatment with vitamin K antagonist therapy [5,6].

However, despite a limited number of patients, the anti-Xa inhibitors, rivaroxaban, apixaban and edoxaban, and the thrombin inhibitor dabigatran etexilate were effective and well tolerated treatment of VTE due to inherited thrombophilia [7]. Also in the
Hokusai study in a subgroup of young patients with hereditary thrombophilia and high risk of VTE recurrence edoxaban resulted efficacious and safe [8]. Although rare, VTE is also a life-threatening disease in paediatrics. Nevertheless, DOAC cannot be prescribed in subjects under the age of 18 years old. In this context, unfortunately still lacking in evidence and targeted clinical studies, many children are treated with heparin or low molecular weight heparins, which require parenteral administration and, in case of unfractionated heparin, also frequent laboratory monitoring and dose adjustment. In case of chronic treatment due to VTE recurrence, these patients are treated with anti-Vitamin K suffering several limitations, such as long on-set and offset of action, unpredictable pharmacologic profile with high risk of food and drug interactions, and need for routine laboratory assessment of anticoagulant activity [9]. In addition to largely demonstrated high efficacy and safety profile, DOACs have not these limitations.

Especially pediatric patients with inherited thrombophilia and "ad vitam" oral anticoagulant treatment significantly increase therapeutic adherence using DOAC $[10,11]$. The management of the anticoagulant therapy of these patients can indeed reconcile the importance for efficacy and safety based on the guidelines and evidence-based medicine with personal and family needs that are then fundamental for therapeutic adherence and for the quality of life. Moreover, pharmacoeconomic studies confirm the role of DOAC in 
the chronic antithrombotic or "ad vitam" treatment, as this therapy in the long term decreases the unit work hours cost of medical and paramedical staff, but also reduces absences or permits from the work of the same patient or his caregiver [12]. Moreover, although there are few targeted studies aimed at extending DOAC in younger patients, results were comparable to the adult and elderly popu- lation $[13,14]$. Not by chance, the Italian Drug Agency (AIFA) has emphasized the weight of the patient's decision on the choice of anticoagulant therapy, even regardless of the more strictly clinical indications, since the physician's evaluation of the discomforts of the patient's logistical and social problems should be a priority.

\begin{tabular}{|c|c|c|c|}
\hline \multicolumn{1}{|l}{ Table 1: Prevalence and thrombosis risk for inherited thrombophilia [15,16]. } \\
\hline Thrombophilia & Prevalence & Relative (absolute annualized) recurrent VTE & Relative risk of risk of initial VTE \\
\hline FVL Heterozygous & $2-7 \%$ & $3.48-5.51(0.05-0.2 \%)$ & $1.1-1.8$ \\
\hline FVL Homozygous & $0.06-0.25 \%$ & $6.79-19.29-0.8 \%$ & 1.8 \\
\hline PGM Heterozygous & $1-2 \%$ & $2.25-3.48-0.13 \%$ & $0.7-2.3$ \\
\hline PGM Homozygous & Rare & $2.19-20.72$ & Uncertain \\
\hline Compound FVL \& PGM Heterozygosity & $0.10 \%$ & $1.13-5.04-0.42 \%$ & 2.7 \\
\hline PC deficiency & $0.2-0.5 \%$ & $10(0.4-2.3 \%)$ & 1.8 \\
\hline PS deficiency & $0.1-0.7 \%$ & $9.6(0.7-3.2 \%)$ & 1 \\
\hline AT deficiency & $0.02 \%$ & $10-30(1.2-4.4 \%)$ & 2.6 \\
\hline
\end{tabular}

Note: VTE venous thromboembolism, FVL factor V Leiden, PGM prothrombin Gene G20210A, PC protein C, PS protein S, AT antithrombin.

Finally, in many cases the definition of screening for inherited thrombophilia is questionable and should be reviewed, following the indications of the major scientific societies also included in the prevalence of the defect in the general population (Table 1). To date, substantial evidence supporting widespread DOAC use in these patients is lacking and additional evaluation of DOAC use is necessary in order to provide more evidence, but after diagnosing a true inherited thrombophilia, the patient affected by VTE should benefit from the DOAC in extended therapy due to efficacy and safety.

\section{References}

1. Tritschler T, Kraaijpoel N, Le Gal G, Wells PS (2018) Venous Thromboembolism: Advances in Diagnosis and Treatment. JAMA 320(15): 15831594.

2. Kearon C, Akl EA, Comerota AJ, Prandoni P, Bounameaux H et al. (2012) Antithrombotic therapy for VTE disease: Antithrombotic Therapy and Prevention of Thrombosis, 9th ed: American College of Chest Physicians Evidence-Based Clinical Practice Guidelines. Chest 141(2): e419Se496S.

3. Witt DM, Nieuwlaat R, Clark NP, Ansell J, Holbrook A, et al. (2018) American Society of Hematology guidelines for management of venous thromboembolism: optimal management of anticoagulation therapy. Blood Adv 2(22): 3257-3291.

4. Konstantinides SV et al. (2015) ESC Guidelines on the diagnosis and management of acute pulmonary embolism. Eur Heart J 36(39): 26422667.

5. Tarango C, Schulman S, Betensky M, Goldenberg NA (2018) Duration of anticoagulant therapy in pediatric venous thromboembolism: Current approaches and updates from randomized controlled trials. Expert Rev Hematol 11(1): 37-44

6. Prandoni P, Barbar S, Milan M, Campello E, Spiezia L, et al. (2015) Optimal duration of anticoagulation. Provoked versus unprovoked VTE and role of adjunctive thrombophilia and imaging tests. Thromb Haemost 113(6): 1210-1205.
7. Bertoletti L, Benhamou Y, Béjot Y, Marechaux S, Cheggour S, et al. (2018) Direct oral anticoagulant use in patients with thrombophilia, antiphospholipid syndrome or venous thrombosis of unusual sites: A narrative review. Blood Rev 32(4): 272-279.

8. Hokusai VTE Investigators, Büller HR, Décousus H, Grosso MA, Mercuri M, et al. (2013) Edoxaban versus warfarin for the treatment of symptomatic venous thromboembolism. N Engl J Med 369(15): 1406-1415.

9. Mikler J, Samoš M, Bolek T, Škorňová I, Stančiaková L, et al. (2019) Direct Oral Anticoagulants: Novel Approach for the Treatment of Thrombosis in Pediatric Patients? Pediatr Cardiol.

10. Bartoli Abdou JK, Patel JP, Crawshaw J, Vadher B, Brown A, et al. (2018) Exploration of adherence and patient experiences with DOACs one year after switching from vitamin-K antagonists- insights from the switching study. Thromb Res 162: 62-68.

11. Male C, Thom K, O’Brien SH (2014) Direct oral anticoagulants: What will be their role in children? Thromb Res 173: 178-185.

12. Amin A, Jing Y, Trocio J, Lin J, Lingohr Smith M, et al. (2014) Evaluation of medical costs associated with use of new oral anticoagulants compared with standard therapy among venous thromboembolism patients. J Med Econ 17(11): 763-770.

13. Vanassche T, Verhamme P, Wells PS, Segers A, Ageno W, et al. (2018) Impact of age, comorbidity, and polypharmacy on the efficacy and safety of edoxaban for the treatment of venous thromboembolism: An analysis of the randomized, double-blind Hokusai-VTE trial. Thromb Res 162: 7-14.

14. Lensing AWA, Male C, Young G, Kubitza D, Kenet G, et al. (2018) Rivaroxaban versus standard anticoagulation for acute venous thromboembolism in childhood. Design of the EINSTEIN-Jr phase III study. Thromb J $16: 34$.

15. Heit JA (2007) Thrombophilia: common questions on laboratory assessment and management. Hematol Am Soc Hematol Educ Progr Pp. 127135 .

16. Bates SM, Greer IA, Middeldorp S, Veenstra DL, Prabulos AM, et al. (2012) VTE, thrombophilia, antithrombotic therapy, and pregnancy: Antithrombotic Therapy and Prevention of Thrombosis, 9th ed: American College of Chest Physicians Evidence- Based Clinical Practice Guidelines. Chest 141(2): e691S-e736S. 